\title{
Stop motion na sala de aula: Utilizando fotografias em movimento como estratégia de construção do conhecimento em uma escola do campo de Santa Rosa - RS
}

Stop motion in the classroom: The use of moving pictures as a strategy of knowledge construction

in a rural school in Santa Rosa - RS

Stop motion en el salón de clase: Utilizando fotografías en movimiento como estrategia de construcción del conocimiento en una escuela del campo de Santa Rosa - RS

Recebido: 08/04/2021 | Revisado: 13/04/2021 | Aceito: 29/04/2021 | Publicado: 30/04/2021

Maritê de Oliveira
ORCID: https://orcid.org/0000-0002-6003-6668
Escola Municipal de Ensino Fundamental Cívico-Militar Coronel Raul Oliveira, Brasil
E-mail: mariteoliveira@gmail.com
Liziany Muller Medeiros
ORCID: https://orcid.org/0000-0001-7325-6611
Universidade Federal de Santa Maria, Brasil
E-mail: lizianym @ hotmail.com
Janete Webler Cancelier
ORCID: https://orcid.org/0000-0002-4850-5492
Universidade Federal de Santa Maria, Brasil
E-mail: janetewc@ gmail.com

\section{Resumo}

Pensando nas dificuldades existentes nas escolas do campo, dentre as quais, possivelmente, encontra-se o uso das tecnologias como ferramenta educacional, sem a necessária utilização da internet, surgiu a proposta de uma análise de como são utilizadas as tecnologias de informação e comunicação (TICs) em escolas do campo. Pelo fato de muitas vezes o meio rural não ter a facilidade de acesso à internet, o laboratório de informática das escolas acaba ficando esquecido e inutilizado, fazendo com que os educandos queiram estudar nas escolas da cidade. Para compreender melhor este contexto, o objetivo geral da pesquisa foi de entender os efeitos da capacitação de educadores e educandos de uma escola do campo em relação às possibilidades de utilização das tecnologias da informação e comunicação para além do uso da internet. A pesquisa foi realizada na Escola de Ensino Fundamental São José, uma escola do campo do município de Santa Rosa, região noroeste do estado do Rio Grande do Sul. Foi uma pesquisa qualitativa, no formato de pesquisa-ação, onde a coleta de dados se deu através de entrevista semiestruturada com a equipe diretiva, educadores e educandos da escola. Além disso, foi oferecida uma oficina de capacitação aos educandos do sétimo, oitavo e nono anos da escola e aos educadores destas turmas, com o intuito de propor uma forma de utilização de tecnologia sem o uso da internet, através da técnica de animação stop motion, com o uso de recursos como um celular ou uma máquina fotográfica, e de um computador.

Palavras-chave: Educação no campo; Tecnologia de informação e comunicação; Stop Motion.

\begin{abstract}
Among the existing barriers in rural schools, possibly, is the use of technologies as an educational tool. The analyses proposed here is how Information and Communication Technology (ICT) are applied in rural schools, without the necessary use of the internet. Because in the rural environment often does not have the facility to access the internet, the computer science laboratory in schools ends up being forgotten and unused, causing the students to want to study in the urban schools. To better understand this context, the main goal of this study is to recognize the effects of the training of educators and students of a rural school in relation to the possibilities of using information and communication technologies beyond the use of the Internet. The research was conducted at the Escola de Ensino Fundamental São José, a rural school in the municipality of Santa Rosa, in the northwest region of the state of Rio Grande do Sul. It was a qualitative research, through the research-action methodology. The data collection was through a semi-structured interview with the school's management team, educators, and students. In addition, a training workshop was offered to the students of the seventh, eighth and ninth grades of the school and to the educators for these classes with the purpose of suggesting a way of using technology without the use of the internet, through the technique of stop-motion animation, with the use of resources such as a cell phone or a camera, and a computer

Keywords: Rural Education; Information and Communication Technology; Stop Motion.
\end{abstract}




\begin{abstract}
Resumen
Pensando en las dificultades existentes en las escuelas del campo, entre las cuales, posiblemente, se encuentra el uso de las tecnologías como herramienta educativa, sin la necesaria utilización de Internet, surgió la propuesta de un análisis de cómo se utilizan las tecnologías de información y comunicación (TICs) en las escuelas del campo. Por el hecho de que muchas veces el medio rural no tiene la facilidad de acceso a internet, el laboratorio de informática de las escuelas acaba quedando olvidado e inutilizado, haciendo que los educandos quieran estudiar en las escuelas de la ciudad. Para comprender mejor este contexto, el objetivo general de la investigación fue entender los efectos de la capacitación de educadores y educandos de una escuela del campo en relación a las posibilidades de utilización de las tecnologías de la información y comunicación más allá del uso de internet. La investigación fue realizada en la Escuela de Enseñanza Fundamental San José, una escuela del campo del municipio de Santa Rosa, región noroeste del estado de Rio Grande do Sul. Fue una investigación cualitativa, en el formato de investigación-acción, donde la recolección de datos se dio a través de entrevista semiestructurada con el equipo directivo, educadores y educandos de la escuela. Además, se ofreció una capacitación a los educandos del séptimo, octavo y noveno años de la escuela ya los educadores de estas clases, con el propósito de proponer una forma de utilización de tecnología sin el uso de internet, a través de la técnica de animación stop motion, con el uso de recursos como un celular o una cámara, y de un ordenador.
\end{abstract}

Palabras clave: Educación en el campo; Tecnología de información y comunicación; Stop Motion.

\title{
1. Introdução
}

Esta pesquisa surgiu no interesse em saber como são utilizadas as tecnologias de informação e comunicação em escolas do campo, onde não há laboratórios de informática e nem acesso à internet ou em locais onde os mesmos são precários.

As escolas, ambientes de educação formal, precisam considerar a realidade de sua inserção, bem como o contexto dos educandos de modo que possam adequar a metodologia de ensino tornando o processo de aprendizagem significativo, o educando e sua realidade, portanto, devem constituir o ponto de partida para organização de ensino (Lemos, 2005). A construção do conhecimento deve ser um processo libertador (Freire, 1981), que permita ao cidadão exercer seus direitos e deveres com plenitude, compreendendo o contexto em que está inserido em toda a sua complexidade, de maneira que suas decisões possam ser conscientes e efetivas para sua realidade.

A escola, conseguindo englobar componentes curriculares à Informática Educativa, aproveita de forma eficaz os Laboratórios de Informática Educativa (LIE), permitindo que através do uso do computador o laboratório torne-se um ambiente mais descontraído, adaptando diferentes situações de aprendizagem, permitindo novos experimentos em função do aprendizado de cada aluno ao seu momento. Ao mesmo tempo, isso possibilita que os educadores possam englobar esse recurso em suas aulas usufruindo de um assistente na emissão, na construção e na troca de conhecimentos. Mas sempre demonstrando o objetivo, explicitando que o laboratório é um ambiente de estudo, não permitindo que possuam a ideia de ser apenas um momento para "fugir da aula" (Salazar da Costa, 2009).

A expressão educação do campo é muito mais que uma simples mudança de nomenclatura - de educação rural para educação do campo. Ela constituiu um dos traços marcantes da identidade de um movimento nacional que vem se consolidando na luta por políticas públicas que garantam o direito da população rural à uma educação que seja no e do campo (Silva, 2016). Na educação do campo segundo Caldart (2004), mais que o direito da população ser educada no lugar onde vive, a educação deve ser pensada desde o seu lugar e com sua participação, vinculada a sua cultura e as suas necessidades humanas e sociais.

\section{Metodologia}

\subsection{Tipo de estudo}

No intuito de atender o objetivo do presente estudo e levando em consideração a natureza do tema abordado, optou-se pelo desenvolvimento de uma pesquisa qualitativa sob a forma de pesquisa-ação. A pesquisa qualitativa é uma forma de compreender questões que não podem ser mensuradas em números, necessitando de uma imersão na realidade e observação da 
forma como outras pessoas compreendem o mundo. As formas mais comuns de coletas de dados qualitativos são através da observação, entrevista, questionário (Gerhardt, 2009).

A pesquisa-ação é utilizada quando existe um interesse coletivo na resolução de uma situação-problema e/ou na orientação para mudanças que objetivem o aprimoramento de um determinado cenário. Atualmente, é utilizada, sobretudo, na área da educação, uma vez que possui potencial para atuação junto ao contexto em estudo e para sua modificação, com a corresponsabilização dos sujeitos da pesquisa nesse processo. Além disso, diminui a distância entre pesquisadora e pesquisados, constituindo um meio para construção coletiva de mudanças, sejam elas de comportamento ou conceitos (Esteban, 2010; Minayo, 2014). A mesma ainda possui a finalidade de "[...] contribuir com informações que orientem a tomada de decisões e os processos de mudança para a sua melhoria [...] o objetivo prioritário da pesquisa-ação consiste em melhorar a prática" (Esteban, 2010, p.167).

\subsection{Local de estudo}

O contexto de estudo foi a Escola Municipal de Ensino Fundamental São José, a qual integrante da rede municipal de educação do município de Santa Rosa - RS. Conforme os dados coletados no projeto político pedagógico da escola, a mesma foi fundada em 28 de setembro de 1977 e localiza-se na localidade de Rincão dos Rocha, zona rural do município. Atende diferentes comunidades, tais como Rincão dos Rolim, Lajeado Paulino, Rincão dos Souza, Rincão Honório, Campo da Aviação, Esquina Central, Linha Giruazinho, Linha São Salvador, Bairro Auxiliadora, Bairro Nova Auxiliadora e Rincão dos Rocha. Atualmente, atende um total de 116 alunos da educação infantil de 4 anos até o $9^{\circ}$ ano do Ensino Fundamental. Deste total, participaram da pesquisa vinte e seis educandos do sétimo, oitavo e nono anos do Ensino Fundamental, além de oito educadores das turmas citadas e a equipe diretiva da escola.

Em seu quadro pessoal, a escola conta com uma diretora, um coordenador, quinze professores e três funcionárias. Possui profissionais de educação qualificados, com licenciatura em suas áreas de atuação e onze professores com especialização, favorecendo uma melhoria da qualidade do ensino.

$\mathrm{Na}$ escola existe um bom relacionamento entre professores, educandos e pais, onde todos se encontram engajados e comprometidos com a melhoria da qualidade de ensino. A situação socioeconômica das famílias gira em torno de 1 a 5 salários mínimos. Em sua maioria são pequenos agricultores, ou empregados em granjas de suínos, o que é o forte na região onde a escola está inserida (EMEFSJ, 2016).

\subsection{Ciclo da pesquisa-ação: da planificação à reflexão}

Para Esteban (2010), a pesquisa-ação, seguindo o modelo de Lewin, constitui-se por quatro passos, com caráter cíclico e destacada flexibilidade e interatividade, quais sejam: 1) Planejamento ou Planificação; 2) Ação; 3) Observação; 4) Reflexão (Figura 1). O processo de desenvolvimento dessas etapas é referido pelo conceito de "espiral da mudança", já que possui caráter dinâmico e articulação entre as fases, sobretudo de ação e reflexão. 
Figura 1 - Passos da Pesquisa-Ação.

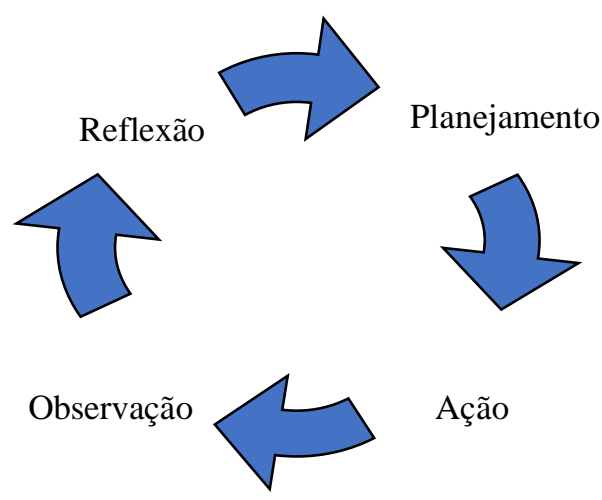

Fonte: Adaptado de Esteban (2010).

\subsubsection{Planejamento ou Planificação}

Consiste na primeira etapa de uma Pesquisa-Ação e envolve, sobretudo, uma indagação reflexiva para identificação de uma situação-problema. Essa identificação pode ser feita de inúmeras formas, entre elas a partir de reflexões dos próprios indivíduos envolvidos na prática ou através de algum observador externo. Identificada a situação-problema, deve ser elaborado um planejamento, ou seja, um plano de ação sobre como se dará a intervenção a fim de modificar o cenário encontrado (Esteban, 2010). No caso do presente estudo, a planificação ocorreu a partir de conversas com a equipe diretiva da escola, a qual destacou que a escola conta com Laboratório de Informática Educativa (LIE). São três computadores, porém os mesmos foram desmontados e no momento somente um computador funciona sem acesso a internet. As iniciativas na área das TICs são quase inexistentes, há precariedade nos equipamentos de informática, que, além de serem em número insuficiente para a demanda da escola, apresentam problemas de funcionamento por falta de manutenção. Há também problemas na rede de internet, que é inexistente para uso dos educandos e educadores.

O acesso a internet é disponibilizado apenas para equipe diretiva em um computador para finalidades burocráticas da escola. Tal situação demonstra a falta de investimento na área de TICs pela secretaria de educação municipal que é a mantenedora da escola. $\mathrm{O}$ descaso apresentado, no que se refere à inserção da escola no mundo digital, se torna um agravante quando é visível que, cada vez mais aumentam os índices de evasão dos educandos, de acordo com estatísticas amplamente divulgadas.

Com a identificação dessa situação-problema, iniciou-se a busca por possíveis alternativas para resolução e/ou modificação da realidade e, a partir de leituras de autores de referência e da experiência prévia da pesquisadora na área, optouse pela realização de uma atividade envolvendo educandos e educadores, com base em uma técnica de animação cujo desenvolvimento não necessita de internet. Além disso, planejou-se a realização de entrevistas com educandos e educadores, a fim de compreender de forma mais apurada a realizada local, bem como verificar o impacto do desenvolvimento das atividades propostas.

\subsubsection{Ação}

A segunda etapa da Pesquisa-Ação compreende o desenvolvimento do plano de ação, ou seja, a organização detalhada sobre o que fazer, por quem, quando e como fazer. São decisões práticas e concretas sobre a proposta e sua organização, bem como os recursos necessários para sua aplicação e as formas de coletas de dados (ESTEBAN, 2010). A etapa da ação foi realizada em dois momentos distintos durante o desenvolvimento dessa pesquisa, no primeiro momento, nos meses de agosto e 
setembro do ano de 2017, foram realizadas oficinas de capacitação utilizando a técnica de animação Stop Motion, com uma estratégia de ferramentas digitais na sala de aula.

\subsubsection{Primeira etapa}

Durante o mês de julho, do ano de 2017, foi realizada uma apresentação para os envolvidos sobre a proposta da pesquisa e nessa oportunidade, realizaram-se entrevistas com a equipe diretiva da escola, educandos e educadores, as quais objetivaram coletar dados sobre a instituição de ensino e conhecer melhor o perfil dos profissionais e educandos que frequentam a escola São José. Os dados coletados nas entrevistas, permitiram uma análise em relação ao acesso e ao interesse de uso das tecnologias pelos entrevistados. Nos meses de agosto e de setembro do ano de 2017, foram realizadas oficinas, com a finalidade de demonstrar, explicar e qualificar o grupo sobre a técnica de Stop Motion.

Após a finalização os projetos de Stop Motion desenvolvidos pelos educandos, a comunidade escolar foi reunida para a apresentação dos vídeos. Nesse momento, os educandos puderam rever seus trabalhos e apreciar os resultados obtidos por seus colegas. Tal experiência os fez sentirem-se valorizados e orgulhosos diante dos elogios que ali receberam. As imagens da Figura 2 demonstram esse momento, ressaltando a importância da participação da família na escola.

Figura 2 - Socialização do projeto e dos vídeos de Stop Motion.

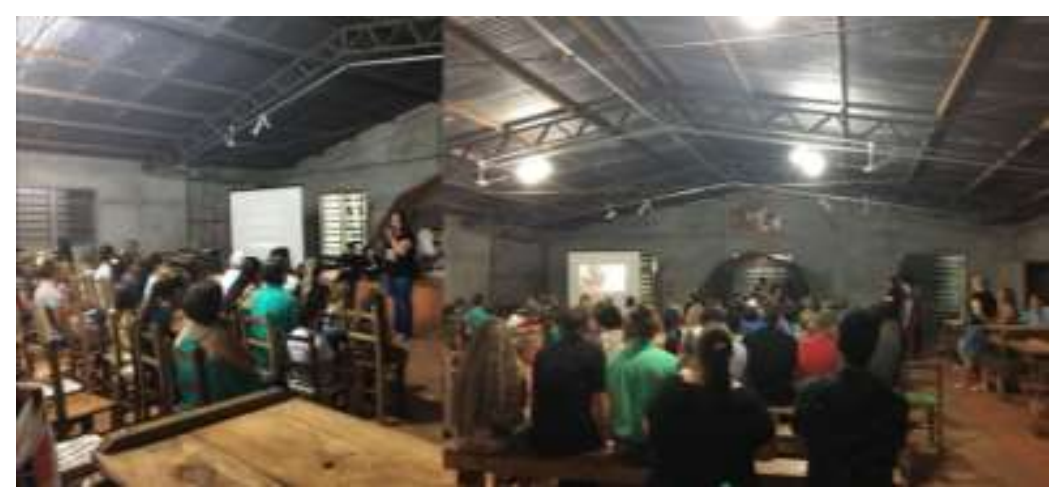

Fonte: Arquivo pessoal da pesquisadora (2017).

Diante dessa primeira etapa da prática desenvolvida, pode se ter uma clara ideia de que trata-se de estudantes com uma enorme capacidade de aprendizagem, além de possuírem a ansiedade por novas descobertas. Dentre elas a de aprofundar o uso das tecnologias, que para eles pode ser vista com um recurso no aprendizado e um conhecimento breve de algo que necessariamente precisarão ao longo de sua vida.

\subsubsection{Segunda etapa}

A primeira etapa da ação alcançou um importante objetivo, além de despertar o interesse dos educandos e proporcionar os mesmo a explorar seu processo de criação aguçou a curiosidade da equipe diretiva e de duas educadoras da escola sobre a técnica do Stop Motion, o que as fez entrar em contato com a pesquisadora para a realização de uma nova etapa, com um grupo reduzido e com um tema estipulado pela instituição de ensino.

A escola estava participando de um concurso promovido pela rede municipal de ensino, onde desenvolveram um projeto relacionado ao descarte de forma correta do óleo de cozinha. Uma das tarefas desse concurso foi divulgar de forma criativa o projeto da escola, e foi nesse momento que despertou o interesse de duas educadoras da escola em utilizar a técnica do Stop Motion para desenvolver uma animação a fim de promover o trabalho desenvolvido pela equipe. As educadoras 
participantes desse trabalho atuavam nas turmas da pré-escola, da educação infantil e na turma do primeiro ano do ensino fundamental. O turno de trabalho destas turmas era o turno da manhã, sendo assim, elas não fizeram parte do grupo das oficinas do ano anterior e em conversa com os colegas souberam do trabalho que havia sido desenvolvido. Para contemplar o período de aula dessas turmas, as oficinas ocorreram no turno da manhã e os educandos que haviam participado da primeira etapa e conheciam a técnica foram convidados a virem nesse turno para a escola, a fim de auxiliarem as educadoras e participar dessa nova etapa.

Porém, como as aulas do sétimo, oitavo e nono anos, ocorriam no turno da tarde e a maioria dos educandos necessitava de transporte escolar para o deslocamento até a escola, somente os que tiveram interesse e moravam perto da escola conseguiram estar presente nessa nova etapa. Cada turma das que haviam participado na primeira etapa teve um representante no desenvolvimento dessa fase.

Foram três encontros, no mês de julho de 2018, sob a orientação da pesquisadora, as educadoras em conjunto com suas turmas e os educandos do turno oposto que estavam presentes, desenvolveram a tarefa, uma animação para o projeto "Descarte Consciente - Planeta Contente". A técnica utilizada foi o Stop Motion, com uma música cantada pelos educandos das turmas do pré e do primeiro ano. O Stop Motion foi representado de forma animada, na qual o planeta não ficará feliz se não cuidarmos dele, misturando óleo e água, remetendo ao tema do projeto, óleo e água não se misturam. A letra da música foi criada pelas educadoras com suas turmas durante suas aulas. Os personagens confeccionados pelos educandos no turno oposto que estavam presentes, feitos com massinha de modelar, representando a letra da música. Após, os educandos que haviam participado da primeira etapa de oficinas, observados pelas educadoras e com auxilio e orientação da pesquisadora criaram o cenário e tiraram as fotografias para a produção da animação, concluindo, exportaram as imagens registradas para o software de edição, onde foi realizada a edição do vídeo, tendo cuidado com a sequência das fotografias, inserção de imagens, texto, efeitos e áudio, conforme mostra na Figura 3.

Figura 3 - Criação dos personagens e captura de fotografias para o vídeo.

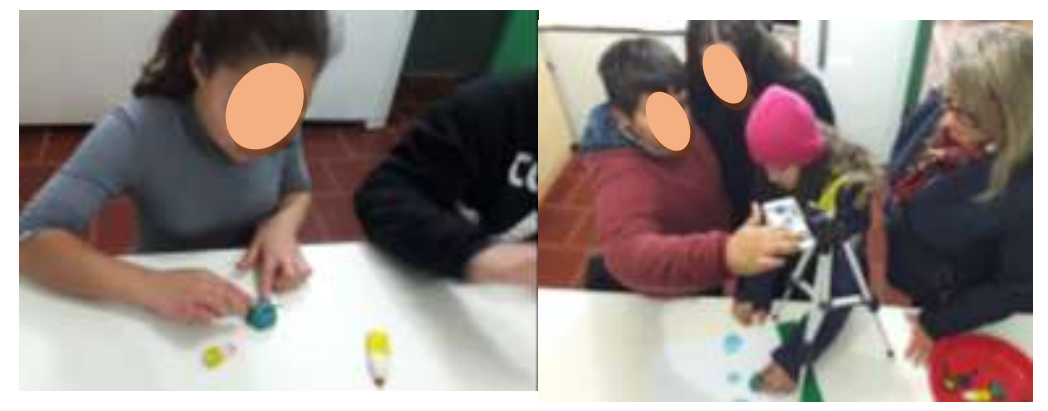

Fonte: Autores (2018).

\subsubsection{Observação}

A observação foi realizada a partir de visitas realizadas ao local de estudo. Após cada visita, a pesquisadora escreveu um Diário de Campo, onde além das atividades realizadas efetivamente, foram escritas as impressões e observações da mesma.

\subsubsection{Reflexão}

A Pesquisa-Ação procura aprender a realidade, tendo em vista uma compreensão profunda do que acontece e por que acontece, para isso é necessário refletir. A reflexão pretende entender o sentido dos processos educacionais, dos problemas que surgiram na implantação do plano, comparando o planejado e o alcançado (Esteban, 2010). 
Para a realização desta reflexão, optou-se pela proposta de análise de conteúdo, do tipo operativa/temática, de Minayo (2014). A autora organiza a análise em 3 fases: a pré-análise em que os dados transcritos são analisados e descritos; a exploração do material, cujos dados descritos são codificados e organizados em categorias representativas; e tratamento e interpretação, em que são feitas algumas inferências sobre os dados. Esta proposta de análise consiste em descobrir núcleos de sentido que compõem uma comunicação, cuja presença, frequência signifiquem alguma coisa para o objeto analítico visado (Minayo, 2014).

\section{Resultados}

A pesquisa realizada obteve resultados em três momentos distintos, uma sequência de coleta de dados que contribuiu para um resultado com maior qualidade. A pesquisa-ação pressupõe uma participação planejada do pesquisador na situação problemática a ser investigada. O processo de pesquisa recorre a uma metodologia sistemática, no sentido de transformar as realidades observadas, a partir da sua compreensão, conhecimento e compromisso para a ação dos elementos envolvidos na pesquisa (Fonseca, 2002).

O questionário contendo uma entrevista semi-estruturada permitiu conhecer o público que frequenta a escola e seus conhecimentos e anseios em relação ao uso das tecnologias.

As entrevistas semi-estruturadas combinam perguntas abertas e fechadas, onde o informante tem a possibilidade de discorrer sobre o tema proposto. O pesquisador deve seguir um conjunto de questões previamente definidas, mas ele o faz em um contexto muito semelhante ao de uma conversa informal. $\mathrm{O}$ entrevistador deve ficar atento para dirigir, no momento que achar oportuno, a discussão para o assunto que o interessa fazendo perguntas adicionais para elucidar questões que não ficaram claras ou ajudar a recompor o contexto da entrevista, caso o informante tenha "fugido" ao tema ou tenha dificuldades com ele. Esse tipo de entrevista é muito utilizado quando se deseja delimitar o volume das informações, obtendo assim um direcionamento maior para o tema, intervindo a fim de que os objetivos sejam alcançados. (Boni \& Quaresma, 2005, p. 75).

A etapa da capacitação da técnica do Stop Motion também permitiu vários resultados, a primeira etapa teve um número grande de educandos participando, porém não de educadores como havia sido planejado pela pesquisadora, deixando-a ansiosa em certos momentos, por não conseguir acompanhar de forma adequada todos os grupos de trabalho e resolver os problemas técnicos que surgiram ao longo dos encontros, deixando evidente a importância da presença do educador em atividades desenvolvidas em instituições de ensino.

Além das dificuldades encontradas, também ocorreram momentos importantes para o processo de aprendizagem, onde os educandos permitiram-se expor o seu processo criativo, dando ênfase a fatos ou temas relevantes a eles que muitas vezes passam despercebidos aos olhos dos adultos. Precisaram ter autonomia para tomada de decisões. Ajudar, solicitar e permitir a intervenção de colegas também foi ações necessárias durante o desenvolvimento dessa fase.

A participação dos educadores atuantes nas turmas participantes da pesquisa ficou livre, partindo deles a não permanência em sala de aula durante a realização das oficinas. Porém, essa primeira fase surtiu através de conversas na escola e exposição dos vídeos a curiosidade de educadores do turno inverso pela técnica de animação utilizada. E instigados por essa curiosidade surgiu a procura por mais uma fase de oficinas, essa com envolvimento de educadores e educandos.

Essa segunda fase de capacitação surtiu um resultado ainda mais valioso, pois atingiu um público a mais, educadores, mesmo sendo em pequena quantidade, são eles que estão diariamente neste meio, podendo estimular a prática e transmitir aos demais colegas o conhecimento adquirido. Motivando cada vez mais a propagação da técnica do Stop Motion, possibilitando aos educandos o uso de ferramentas digitais, de forma lúdica e atrativa, engrandecendo o processo de ensino e aprendizagem. 
Os resultados obtidos ao longo desse estudo foram gradativos e demonstraram a importância da pesquisa e o impacto que a mesma tem em seu campo de estudo, possibilitando mudanças e melhorias em um determinado local e o público que convive e frequenta o mesmo.

\section{Considerações Finais}

Diante dessa prática desenvolvida, pode se ter uma clara ideia de que trata-se de educandos com uma enorme capacidade de aprendizagem, além de possuírem a ansiedade por novas descobertas. Dentre elas a de aprofundar o uso das tecnologias, que para eles pode ser vista com um recurso no aprendizado e um conhecimento breve de algo que necessariamente precisarão ao longo de sua vida. Lastima-se que o uso dessas ferramentas não ocorra na escola, sendo assim, aumenta cada vez mais o anseio por parte de alguns educandos de estudar em escolas da cidade, onde se tem acesso mais facilmente a recursos que para eles nesse momento, pelo menos dentro da escola encontra-se distante.

Na construção de uma nova escola, que atenda aos anseios do mundo contemporâneo, novas maneiras de ensinar são necessárias. Não é possível mudar a realidade que ora se apresenta sem um repensar da prática. E é sabido que a prática pedagógica de qualidade pressupõe uma metodologia adequada às necessidades do educando. Assim, aulas bem planejadas, com objetivos claros, com metodologias criativas, onde o educando passe de sujeito passivo a construtor de seu próprio saber, fazem toda a diferença na melhoria da qualidade da educação.

A escola tem papel fundamental como instituição atuante na sociedade, mas vem enfrentando uma crise de paradigmas que questiona seu envolvimento com a realidade. Seu desafio é buscar soluções inovadoras que minimizem problemas e que dê conta de acompanhar os processos de mudanças pelos quais a sociedade vem passando.

Os objetivos do estudo foram alcançados, de uma maneira real e verdadeira, a qual permitiu constatar muitos anseios, interesses e potenciais. Os quais deverão ser relevantes em projetos futuros desenvolvidos por esta instituição e ensino, como por exemplo ampliação do tempo dedicado as tarefas e a disponibilidade de mais ferramentas tecnológicas, que permitam o manuseio individual, consentindo a cada educando explorar suas potencialidades e sua criatividade, respeitando seu tempo de aprendizagem. Nota-se que o uso das tecnologias no processo de ensino-aprendizagem deixa de ser possibilidades e torna-se necessidades e, assim, viver em rede já é o caminho que nos conduz a novas oportunidades, desafios e conhecimentos de forma fácil e rápida.

\section{Referências}

Anderson, J. (2010). A inclusão das TICs na educação brasileira: problemas e desafios. http://www.redalyc.org/htm1/2810/281024896010/.

Barros, D.M.V. \& Moreira, J. A. (2011). Educação e Tecnologias: reflexão, inovação e práticas. https://www.researchgate.net/publication/288993534.

Caldart, R. S. (2004). Pedagogia do Movimento Sem Terra. Expressão Popular.

Caldart, R. S. (2011). Caminhos para transformação da escola: reflexões desde práticas da licenciatura em Educação do Campo.

Escola Municipal de Ensino Fundamental São José. (2016). Projeto Político Pedagógico.

Esteban, M. P. S. (2010). Pesquisa qualitativa em educação: fundamentos e tradições.

Fernandes, P. (2011). O currículo do ensino básico em Portugal: Políticas, perspectivas e desafios. 2011.

Fonseca, J. J. S. (2002). Metodologia da pesquisa científica. Apostila.

Freire, P. (1981). Pedagogia do Oprimido.

Gerhardt, T. E. Silveira, D. T. (2009). Métodos de Pesquisa. Coordenado pela Universidade Aberta do Brasil.

Lemos, A. (2005). Cibercultura e Mobilidade: a era da conexão. Congresso Brasileiro de Ciências da Comunicação.

Minayo, M. C. S. (2014). Pesquisa qualitativa em saúde. Instituto Sírio Libanes.

Minayo, M. C. S. (2017) Amostragem e Saturação em Pesquisa Qualitativa: consensos e controvérsias. Revista Qualitativa. 
Research, Society and Development, v. 10, n. 5, e44810514799, 2021

(CC BY 4.0) | ISSN 2525-3409 | DOI: http://dx.doi.org/10.33448/rsd-v10i5.14799

Purves, B. (2011). Animação básica 02: Stop-Motion.

Costa, S. da. J. (2009). Informática na Educação: o uso do computador no processo de ensino e aprendizagem nas escolas de Açu/RN na perspectiva dos atores envolvidos nesse processo. InterSciencePlace.

Silva, J. G. (2016) Políticas educativas para integração das TIC na escola: um estudo comparado entre brasil e Espanha. Tese Doutorado Perspectivas Histórica. 